\title{
Evaluation of the possibility of forecasting the displacements of the Solina Dam based on observation of the feeler gauges
}

\author{
Aleksandra Bąk 1 \\ ${ }^{1}$ AGH University of Science and Technology, Faculty od Mining Surveying and Environmental Engineering, Cracow.
}

\begin{abstract}
These studies are the continuation of previously conducted researches based on displacements of the Solina Dam. To support the monitoring of the dam, the EDF model were used. This model determines the dependence between displacements observed on the elements of the dam and the level of the upper water, cyclicality of temperatures and the impact of time. The use of model, in both the imaging of displacements of the Solina Dam and forecasts made for the benchmarks located on the crest of the dam, gave satisfactory results, therefore further analysis were undertaken. Displacement forecasting was made based on data from feeler gauges located at the pillars, retaining walls and four galleries. Analysis based on 4 different forecasting periods enabled for the conclusion that to obtain reliable forecasts, measurement data based on 10 years of operation with frequency of 1 per month is required. The use of such a comprehensive database allowed for the achievement of full compliance between modelled values and observed displacements within the established confidence intervals.
\end{abstract}

\section{Introduction}

Unsatisfactory condition of hydraulic structures, as dams, is confirmed by various institutions, including, among others, the Chief Inspectorate of Construction Supervision [1]. Said technical condition of the facilities, is the result of the influence of various factors on the dam. Undoubtedly the safety of dams is affected by rheological and meteorological factors, excessive filtration, and errors during the design and execution stage, and difficulties to predict extreme natural phenomena [2]. Growing experience of designers has enabled to minimize the risk of errors at the design stage, as well as eliminating the shortcomings in the execution phase. Currently, the improper operation of the dams is the biggest threat to their safety. An important aspect, from the point of view of the safety of dams, is also the impact of natural factors, which could exacerbate the small displacements and deformations.

In order to improve the safety of the dam there is a need to take actions to monitor the behaviour of this type of facilities. The currently used monitoring and control system is based $i$. a. on the conduct of regular geodetic measurements of displacements of the elements of the facility, the collection and interpretation of data. One of the possibilities to improve the safety of hydro-technical facilities could be proper interpretation of measurement data that enable to draw conclusions about the technical condition of the dams. The interpretation of the current state of the dams is supported by numerous methods [3]. These methods are focused on a variety of factors, ranging from extreme phenomena, to natural, cyclical factors, such as seasonal variability, the influence of time or temperature cyclicality.

The article - as a continuation of previously conducted researches [4] - focuses on assessing the impact of natural, cyclical factors on the possibility to reflect changes observed on the structures during normal operation of the facility. Similarly, to previous researches, this analysis was based on model developed by Électricité de France. This is a tool created to interpret the behaviour of arch dams. This model focuses on assessing the impact of rheological changes, temperature cyclicality, and the assessment of impact of the hydrological factor. This article focuses on modelling measured data from the feeler gauges located on the Solina Dam during normal operation of the facility. Analysis confirmed utility of the EDF model in reflecting the displacements observed on the feeler gauges, therefore the predictions based on explanatory factors were undertaken.

\section{Methods and materials}

As it was mentioned, presented analysis, is based on the model proposed by Électricité de France.

\subsection{The EDF model}

The EDF model is the first model created by Électricité de France to assess the state of arch dams. This model describes the dependence between natural cyclical factors and displacements observed on various part of the structure. Previously conducted analysis confirmed that the method developed by Électricité de France is a valuable tool to interpret the behaviour of concrete dams, as the Solina Dam. The EDF model (1) takes into

$\overline{1}$ corresponding author: abak@agh.edu.pl 
account the impact of three key factors: hydrostatic effect, the value of the temperature and the impact of time on elements of the dam. The influence of the rheological and seasonal factors is determined as a date function $(\mathrm{t})$, while the variability caused by the hydrological factors is presented using the upper water level (2).

$$
M(z, t)=T(t)+S(t)+H(z)
$$

$\mathrm{M}(\mathrm{z}, \mathrm{t})$ - the value of the displacement;

$\mathrm{T}(\mathrm{t})$ - rheological impact;

$\mathrm{S}(\mathrm{t})$ - seasonal effect;

$\mathrm{H}(\mathrm{z})$ - the effect of hydrological impact.

$M(z, t)=A+B \cdot e^{-C t}+D \cdot \sin \left(\frac{2 \pi t}{365}+E\right)+F \cdot$

$\sin \left(\frac{4 \pi t}{365}+G\right)+H z+I z^{2}$

A, B, C, D, E, F, G, H, I - coefficients specific to the measuring point;

$\mathrm{t}$ - time;

$\mathrm{z}$ - water level.

Proposed method performs adequately and reflects the behaviour of dams; however, numerous scientists have called into question its usefulness, as a reliable tool for the analysis of the hydraulic measurements. These conclusions are dictated by the inclusion of phenomena of the delayed piezometer response on the changes of hydrological factor [5]. Another limitation of the model, as a result of its simple structure, is associated with seasonal impact. The influence of seasonality, according the EDF model is presented as a date function. This leads to the inclusion of fixed conditions of the dam on a specific day of the year, but despite this limitation, the results were considered to be very good [7].

Despite numerous limitations the model is burdened with, it was decided to continue research on the displacement of the Solina Dam. Bearing in mind these simplifications and approximations, it was decided to continue the assessment of the possibility of forecasting the displacements of the measurement points based on the data from feeler gauges located on the Solina Dam.

\subsection{The Solina Dam}

Analysed structure is the tallest hydro-technical object in Poland. It measures 81.8 meters in height, forming a lake whose water surface reaches over 2100 hectares, while the capacity of the created reservoir is estimated at 474 million cubic meters. The maximum depth of the created lake is $60 \mathrm{~m}$. Construction of the Solina dam has allowed to launch in 1968, at the Solina Hydroelectric Power Plant. It is a pumped storage power plant equipped with four Francis type turbine sets with installed power output of $200 \mathrm{MW}$, which ensures an annual production in order of $112 \mathrm{GWh}$.

This analysis is focused on displacements observed using feeler gauges. The Solina Dam is equipped with feeler gauges located at 4 sections of gallery (Fig. 1), the retaining walls and pillars (Fig. 2). Feeler gauges are observed with frequency of 4 measurements per month.

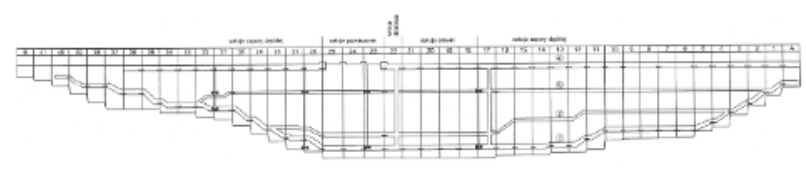

Figure 1. Feeler gauges' deployment in the body of the Solina Dam

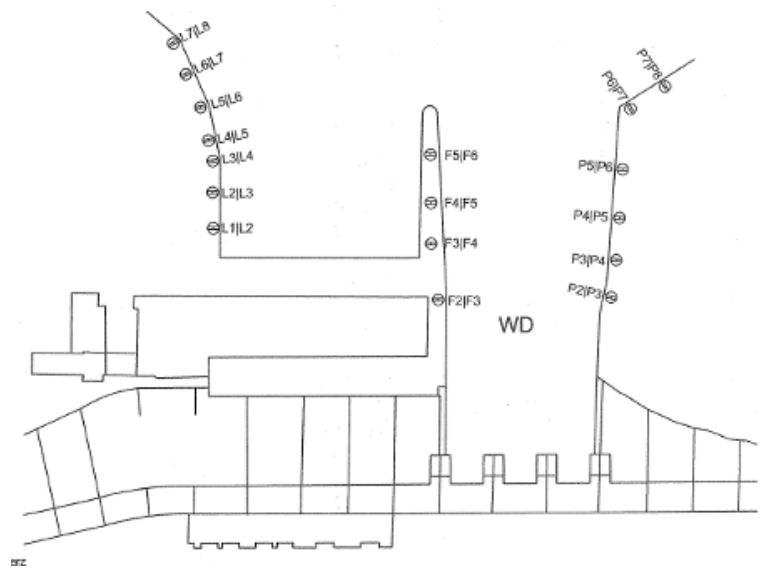

Figure 2. Feeler gauges' deployment in the retaining walls and pillars.

\subsection{Methods}

Analysis indicated a reliable reflection of the behaviour of the dam using said model. This allowed for attempt of the possibility of forecast of the displacements based on data obtained from monitoring of feeler gauges placed on the Solina Dam. Analysis was based on measured data obtained from the years: 1992 - 2011. Displacements were analysed based on data from measurement equipment located in 4 sections of the dam gallery, pillars and retaining walls. Analysis was performed using 4 different sequences of measurement data: 10,12,15 and 18 years.

Presented modeling was conducted using MATLAB program. Mentioned model was implemented to MATLAB programme. The entered data (time and level of upper water) made it possible to generate specific coefficients of the model for individual measurement points. As the results of the analysis there were obtained the graphs that allow to compare actual and predicted values of displacements.

Analysis indicated a reliable reflection of the behaviour of the dam using said model. This conclusion allowed for forecasting, which was then evaluated for compliance of the forecast with the absolute deviation test [8]. The commonly used test shows that $99.7 \%$ of all observations is placed in the $[\mu-3 \sigma, \mu+3 \sigma]$ interval. If the measurement differs by more than 3 standard deviations from the expected value, it can be concluded that it is disturbed due to incorrect definition of the correlated values, or incorrect assessment of the measurement uncertainty.

\section{Results}

In line with the assumptions of the analysis, the forecast of displacements based on observations of feeler gauges of the Solina Dam was made.

As opposed to the modeling of the displacement based on measurement data from the crest of the Solina Dam, 
there is a possibility to forecast changes observed on the feeler gauges based on 10 years of operation. It is caused by the frequency of measurements. Measurements of the crest of the Solina Dam are performed with frequency of 2 per year, while feeler gauges were measured once per month. As extensive measurement database allowed to determine coefficients of the model, that ensure compliance in $87 \%$ of analyzed cases. Based on measurement data from 10 years of exploitation of the dam the best forecasts were performed in case of the feeler gauge located in section 30 -31 , at the gallery no. 4 (Fig. 3). In this case, the average error was $0,0409 \mathrm{~mm}$.
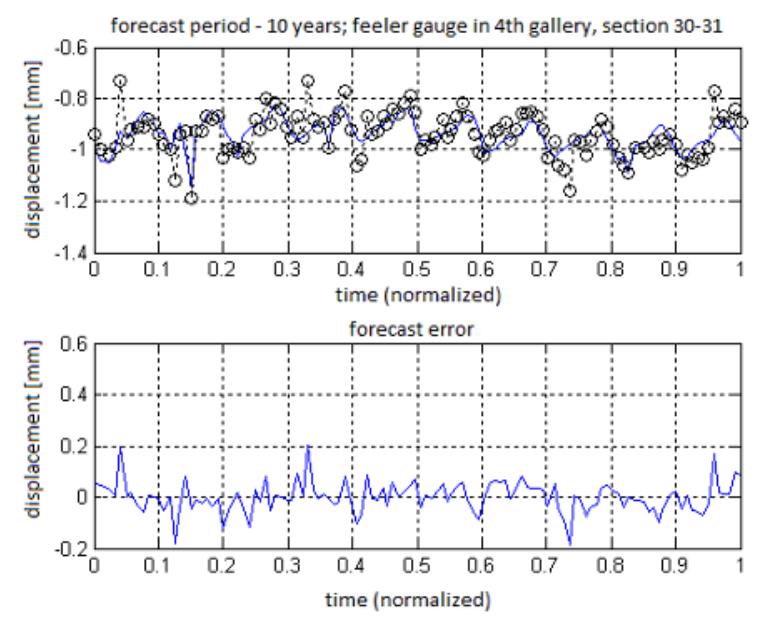

Figure 3. Approximation of displacements observed in the feeler gauge, section 30-31, gallery no. 4 . Forecast period 10 years.

The model, that was generated based on the 10 -years of operation of the dam, worse illustrated the displacement observed on the pillars and retaining walls of the Solina Dam, e.g. feeler gauge no. L 5-6, located on left retaining wall (Fig. 4). In this case an average error was about $0,5 \mathrm{~mm}$.
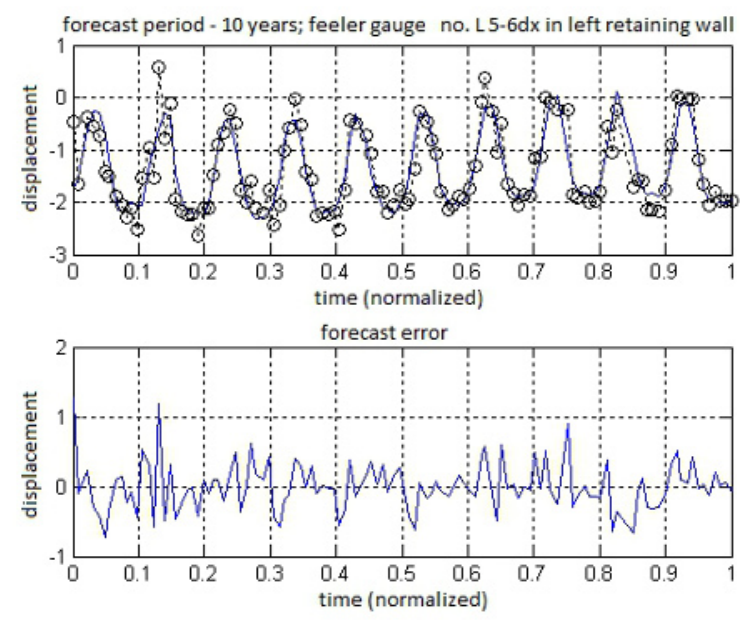

Figure 4. Approximation of displacements observed in the feeler gauge no. L5-6, retaining wall. Forecast period 10 years.

Increasing the forecasting period by 2 years allowed to create the model, that ensure compliance in $90 \%$ of analyzed measurement points Modeling based on 12 years of exploitation of the dam allowed for better reflection of the direction of the displacements. Unfortunately the forecasts were burned with higher error than based on 10 years of exploitation. Similarly, to the previous forecast period, the model better reflects the displacements observed on galleries of the dam, less well changes observed on the pillars and retaining walls were illustrated. Based on forecasting period of 12 years' feeler gauge in section 25-26, gallery 4 (Fig. 5) was the best reflected. An average error was $0,047 \mathrm{~mm}$.
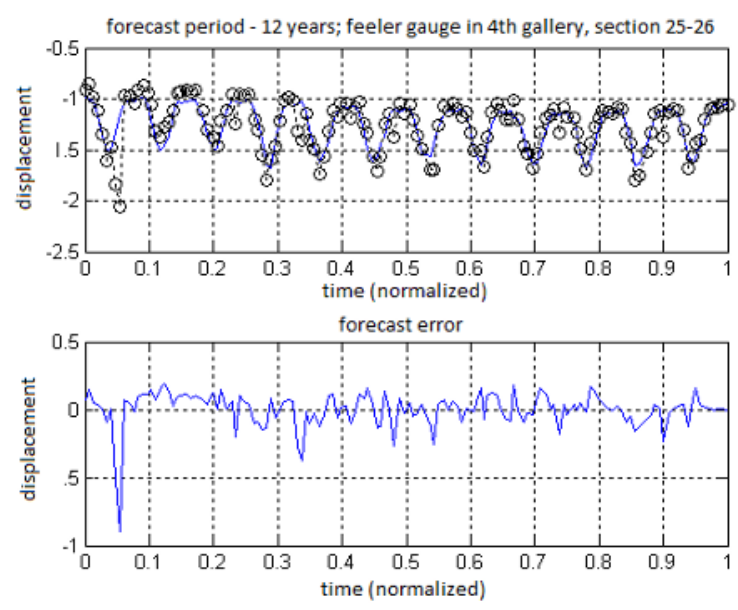

Figure 5. Approximation of displacements observed on the feeler gauge, section 25-26, gallery no. 4. Forecast period 12 years.

In this analysis the worst reflection was observed on the retaining wall no. M 6-7 (Fig. 6), where an average error was about $3 \mathrm{~mm}$.
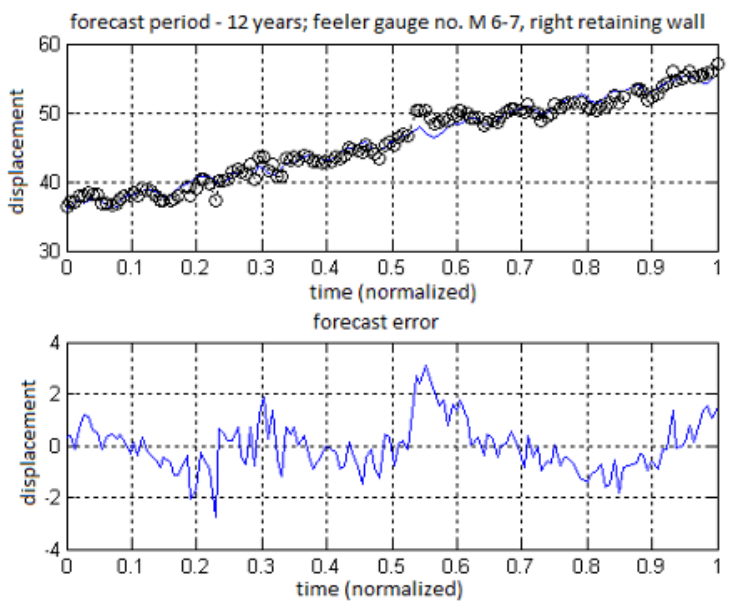

Figure 6. Approximation of displacements observed in the feeler gauge, retaining wall M 6-7. Forecast period 12 years.

Modelling based on the forecast period of 15 years overlaps to a large extent with the modelling based on 12 years of operation. It was best adopted to the displacement observed on the feeler gauges of the galleries, and the worst reflection of the model was again observed in the case of pillars. Increasing the forecasting period up to 15 years allowed for compartmental forecast properly reflecting the actual displacement observed on the elements of the dam. When assuming such comprehensive database, the point forecasts are very close to the actual observations of movements in subsequent measurement periods. Models that were created based on 15 years of exploitation correspond to the observations in $85 \%$ of the feeler gauges. This is caused by incomplete 
measurement database of the feeler gauges located on the retaining walls. Created models illustrate changes in $66 \%$ of measurement points. Incomplete observations made it impossible to forecast displacement in the next measurement step. An example can be retaining wall no. M 7-8 (Fig. 7), where an average displacements were about $30 \mathrm{~mm}$, and an average error reached $15 \mathrm{~mm}$.
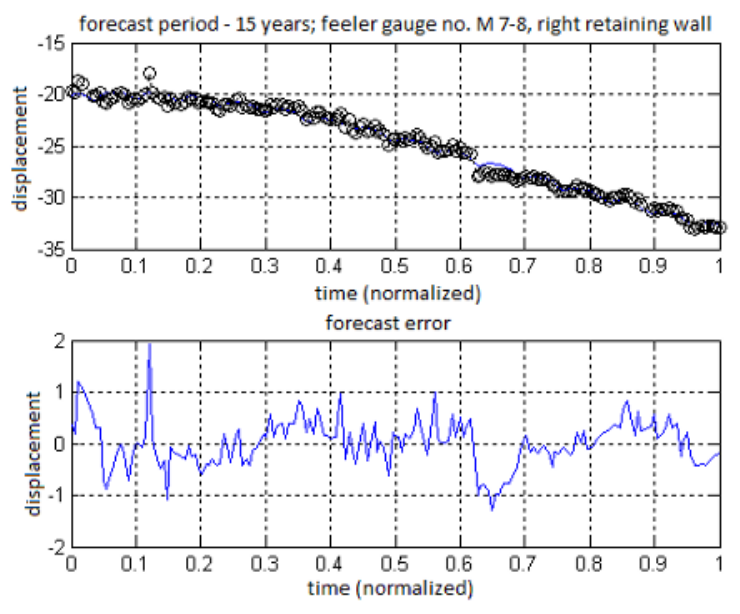

Figure 7. Approximation of displacements observed in the feeler gauge, retaining wall M 7-8. Forecast period $15+1$ years.
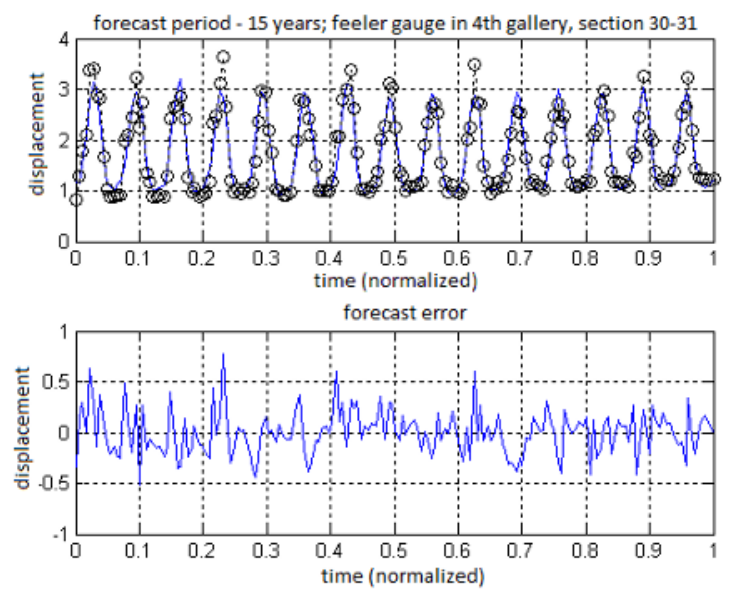

Figure 8. Approximation of displacements observed in the feeler gauge, section $30-31$, gallery no. 4 . Forecast period 15 years.
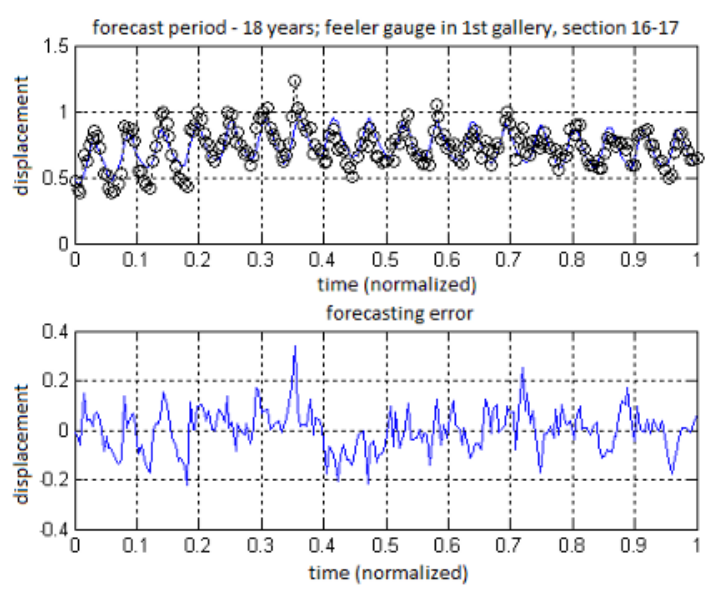

Figure 9. Approximation of displacements observed in the feeler gauge, section 16-17, gallery no. 1 . Forecast period 18 years.
The best reflection based on 15 years of exploitation of the dam was observed on feeler gauge located in gallery 4 in section 4 (Fig. 8). An average error was $0,056 \mathrm{~mm}$.

Modelling based on the longest of the proposed forecasting periods, i.e. 18 years reaffirms that best reflected by the EDF model were the displacements of feeler gauge located in the section 16-17, gallery no. 1 (Fig. 9). In this case an average error was $0,084 \mathrm{~mm}$.

The models created based on 18 years of operation of the dam the worst reflected displacements observed on the feeler gauge no. M 6-7, located on the right retaining wall (Fig. 10). Similarly to previous analysis it was caused by incomplete measurement database. Some of those feeler gauges did not correctly reflects the direction of changes.

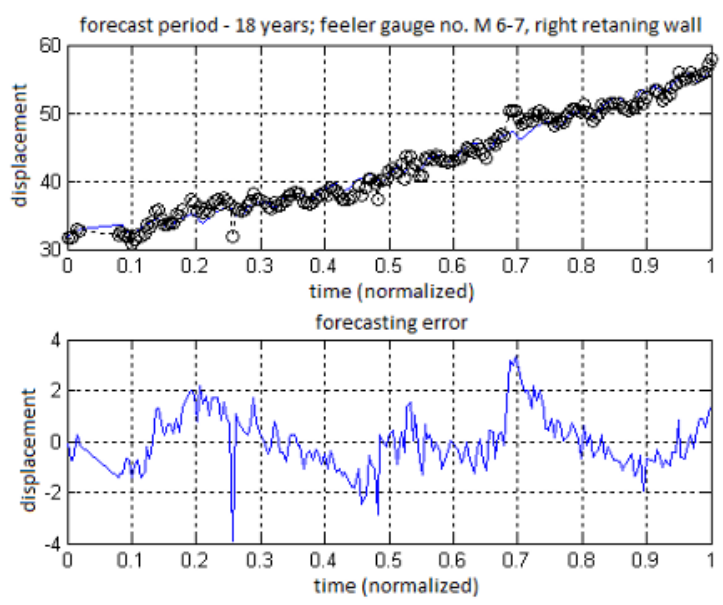

Figure 10. Approximation of displacements observed in the feeler gauge no. M 6-7, retailig wall. Forecast period $18+1$ years.

Obtained results confirm that the EDF model, although originally designed for arch dams well, reflects the behavior of concrete, gravity dams. This report - just like the previous one - also allows us to draw the conclusion that the model can also be a useful tool in terms of forecasting of future displacements. In order to assess the possibility of the forecast, 4 different forecasting periods were used. However unlike to the previous analysis of forecasting - crest of the Solina Dam - it was possible to predict future displacements based 10 years of exploitation of the dam. This situation is caused by large sequence of measurement data. In case of the crest of the dam, measurements were performed in frequency of 2 per year and feeler gauges were measured with frequency of $1 /$ month. The displacement forecast results based on 12 years of operation of the facility have prompted similar conclusions. Database of 12 years of operation allowed to improve not only coefficients of the model, but also forecasts. Further analysis corresponding to 15 and 18 years of operation of the dam, did not allowed to created models that improved the direct of displacements. It was also caused by incomplete measurement data. Some of the feeler gauges located on the retaining walls made it impossible to forecast future displacements. However, based on complete measurements data sequences - all of analysed galleries - forecasts were in line with observed displacements. 


\section{Discussion}

Model, used to analyse displacements of the elements of the Solina Dam, is not without its faults and limitations. Despite these limitations, the flood risk associated with exploitation of hydro technical facilities, as dams, caused that further steps towards monitoring and control were undertaken. The monitoring of dams, and their control play a vital role in ensuring the safety of such facilities.

The article makes assessment of the possibility to expand activities in the field of data interpretation of the displacements of elements of the Solina Dam based on the EDF model. Ultimately, the model has been created having arch dams in mind, but it is also used for other types of structures. The EDF model has several limitations. First of all - it is widely believed that statistical models seeking dependence between the causes and quantitative effects have some weaknesses. Quoted analyses show a significant limitation of the model, one of them is the delay of the response of the structure to the measurements of the explanatory factors. The authors, due to the tendency of analysed dam in a form of excessive filtering, propose the delay of analysis on the basis of the method based on Darcy's law and Richard's equation. This addition takes into account the use of a linear, dynamic analysis system of the share of factors that do not cause aging of dams on changing of the pore pressure. Additionally, as a result of analysis, the authors ruled out the possibility of applying the model for the forecasts due to the mentioned difference in pore pressures, and the lack of taking into account the effects of precipitation. A similar statement was drawn by the authors of the article "Delayed response analysis of dam monitoring data" [6], who support the lack of forecast opportunity based on the EDF model. The main cause is also considered to be the delay phenomenon due to distracting behaviours, such as filtering or viscoelasticity. As a solution they propose the inclusion of an impulse response, other than the aging of materials in the statistical analysis.

Despite these limitations, the EDF model is considered to be stable and capable of providing reliable results. Assuming all restrictions, the model is burdened with, an attempt was made to predict the dam displacement. Previous analysis in terms on prediction displacement based on measured data from the crest of the Solina Dam was correct, thus further modeling was undertaken.

\section{Summary}

The measures taken constitute the continuation of analysis of displacement based on observation feeler gauges located on the elements of the Solina Dam. Forecast based on displacement data of measurement points was continued based on the EDF model. It shows correlation between displacements observed on the elements of the dam, and cyclical natural factors. It is estimated that the greatest impact on the behaviour of the dam are temperature factors, seasonality, and the influence of time. Being fully aware of the limitations, the model is burdened with, an attempt was made to put a forecast of displacements as a function of time.

Opposite to previous analysis of the displacements observed on the crest of the Solina Dam, forecasting of changes of feeler gauges based on 10 years of measurements were possible. Increase of the length of forecasting period across all of analyzed feeler gauges were worst reflected. It was caused by incomplete measurement data of the feeler gauges located on the retaining walls. In the other feeler gauges that were analyzed, increase of the length of measurements database improved the forecasts of previous displacements.

The overall objective of the analysis was to evaluate the possibility of forecasting changes observed on the elements of the Solina Dam based on data obtained from feeler gauges. The undertaken analysis confronts the problems of the unsatisfactory conditions of dams and the necessity to minimize the threat posed by their operation. There are plans to achieve it through actions aimed at improving the safety of hydraulic structures by expanding activities in terms of interpretation of measurement data, and forecasts of changes observed in the dams. Forecasts of displacements of the feeler gauges of the dam are only the beginning for further study. Subsequently, there are plans to forecast the displacements studied in other parts of the structure. Based on differing displacement models and forecasts of individual elements, a holistic model will be created that will enable to treat the facility in a comprehensive manner and thus will allow to assess the state of the facility across the dam.

Implementation of the presented analysis will allow for early detection of disturbing phenomena, destructive processes or discontinuities in the displacements of dams, significant evolutions, irreversibility and other disorders. It will also allow for assessment of the current technical state of dams, which - to a large extend - will streamline the decision-making process and indicate the necessary renovation and repair actions or the necessity to take measures of emergency protection, thus allowing those responsible to make expert judgement, technical and economic analysis.

\section{References}

1. K. Parylak, W. Wolski Oceny stanu technicznego budowli piętrzacych $w$ Polsce $w$ świetle standardów unijnych. XXIII konferencja naukowo - techniczna, Szczecin - Międzyzdroje (2007)

2. Z. Kledyński Monitoring $i$ diagnostyka budowli hydrotechnicznych, cz.1. Nowoczesne Budownictwo Inżynieryjne, s. 54 - 61 (2011)

3. K. Fiedler Awarie i katastrofyzapór-zagrożenia, ich przyczyny $i$ skutki oraz działania zapobiegawcze. IMGW (2007)

4. A. Bąk Analiza przydatności modelu EDF dla celów monitoringu odksztatceń elementówzapory Solina. IV International Conference of Young Scientists ,Nauka dla Środowiska Przyrodniczego" Poznań, (2015)

5. Bonelli S., Royet P. Delayed response analysis of dam monitoring data. ICOLD European Symposium on Dams in a European Context, GEIRANGER, (2001)

6. S. Bonelli, R. Tourment, H. Felix Analysis of earthdam monitoring data. Selected problems of water engineering, p. 133 - 150. Kraków (2003)

7. L. Chouinard, R. Larivière,P. Côté, W. Zhao Analysis of Irreversible displacements in multiple arch concrete dam using principal component analysis. 
Joint International Conference on Computing and Decision Making in Civil and Building Engineering, Montréal, Canada (2006)

8. W. Łuczek Podstawy statystycznego opracowania pomiarów. University of Technology in Gliwice, Gliwice (1995) 